\title{
Proyecto de Intervención sobre Educación Ambiental y Sostenibilidad en la población de Polopos - La Mamola
}

Tania Rubia Montes - Universidad Granada

(D) $0000-0002-1707-4116$

Recepción: 10.11.2020 | Aceptado: 16.02.2021

Correspondencia a través de ORCID: Tania Rubia Montes iD 0000-0002-1707-4116

Citar: Rubia Montes, T (2021). Proyecto de Intervención sobre Educación Ambiental y Sostenibilidad en la población de Polopos - La Mamola. REIDOCREA, 10(14)-1-16.

Resumen: Propuesta de intervención socioeducativa para recuperar la flora característica de zona potenciando los beneficios del mar en la salud de las personas. Proyecto destinado a todas las edades, tanto personas del municipio como del exterior. Se pretende una unión intercomunitaria a la hora de realizar las actividades, así como potenciar todo lo bueno que puede ofrecer el municipio a la población. Es una propuesta de educación ambiental y de desarrollo sostenible.

Palabra clave: Educación Ambiental

Intervention Project on Environment Education and Sustainability in the village of Polopos - La Mamola

Abstract: Proposal for a socio-educational intervention to recover the flora characteristic of the area, enhancing the benefits of the sea on people's health. Project aimed at all ages, both people from the municipality and from abroad. An intercommunity union is intended when carrying out the activities, as well as promoting all the good that the municipality can offer to the population. It is a proposal for environmental education and sustainable development.

Keyword: Enviromental Education

\section{Introducción}

La Educación Ambiental es un proceso interdisciplinario, el cual pretende desarrollar a la sociedad, para que esta sea consciente del medio en el que se encuentra y acercarse hacia la naturaleza. De esta manera, será capaz de informarse, resolver problemas, tomar decisiones, modificar actitudes. Es decir, actuará para que exista una calidad ambiental (Mrazek, 1996, citado en Flores, 2012); "de esta manera decimos que la Educación Ambiental es un proceso que pretende formar y crear conciencia a todos los seres humanos con su entorno, siendo responsables de su uso y mantenimiento" (Rengifo, Quitiaquez y Mora, 2012). También se define en el Congreso Internacional de Educación y Formación sobre Medio Ambiente (Comisión Temática de Educación Ambiental, 1999):

"La educación ambiental es un proceso permanente en el cual los individuos y las comunidades adquieren conciencia de su medio y aprenden los conocimientos, los valores, las destrezas, la experiencia y también la determinación que les capacite para actuar, individual y colectivamente, en la resolución de los problemas ambientales presentes y futuros" (pp. 6).

Esta corriente educativa, como cualquier otra, ha tenido un inicio, marcado por diversos acontecimientos, siendo la fundación Council for Environmental Education del Reino Unido la que impulsó la realización de acciones sobre el medioambiente en los centros educativos de su país en 1968. Con una orientación conservacionista en sus inicios debido a la tradición conservacionista de los países anglosajones (Novo, 1996). 
Una de las principales características de esta corriente educativa fue su inició desde bases educativas por lo que son los propios profesores los que implementan en sus materias estos conocimientos sobre el medioambiente, algo que fue avanzando a lo largo del tiempo, no quedándose estancado únicamente diciendo que la Educación Ambiental se asociaba a los aspectos naturales de bosques y árboles si no también asociándolo a los aspectos sociales de la ciudad, los sistemas económicos (Novo, 1996). Esto fue un suceso a destacar en numerosos países. España, uno de ellos, el cual dejó de centrarse en la conservación del hábitat o de las especies y pasó a interesarse también por el cambio social para superar cualquier situación. Desde ese momento, la Educación Ambiental ha sido necesaria en los centros escolares y en los libros de texto (Barba, 2019).

Desde la educación formal se muestra a los alumnos todas las temáticas que aborda la Educación Ambiental para que, de esta manera puedan ser conscientes de la problemática que existe en la actualidad y poder, de una manera dinámica, cambiar esto y ser conscientes de ello, creando una cultura ambiental (Rengifo, Quitiaquez y Mora, 2012; Aguilera Morales y Perales Palacios, 2016).

La Educación Ambiental en España, ha tenido un largo recorrido. Sus inicios en el ámbito escolar aparecen con el Movimiento de Renovación Pedagógica, abogando por una educación basada en una aproximación del alumnado al entorno, contando con grandes pioneros, necesarios para impulsarla en el país. La primera ley que respaldó propuestas educativas ambientales en las aulas en España fue la Ley Orgánica para la Gestión del Sistema Educativo, LOGSE, la cual tuvo un gran camino que recorrer con grandes dificultades, como llegó a ser la crisis socioambiental. De este modo se procurará una Educación Ambiental que llegase a toda la sociedad, basada en la sostenibilidad (Comisión Temática de Educación Ambiental, 1999). Aparte de publicar el Libro Blanco de la Educación Ambiental en España, también se publicó el Libro Blanco de la Educación Ambiental en España en pocas palabras que trata de manera divulgativa los aspectos más destacados de la versión completa. En esta última versión, de divulgación, menciona que entre la Educación Formal y la Educación Ambiental existe un punto de unión (Ministerio de Medio Ambiente, 1999).

La formación ambiental del profesorado tanto de Educación Primaria y Secundaria es tan fundamental como la del profesorado de universidad. Por lo tanto, la Educación Ambiental es necesaria en cualquier nivel educativo y en muchas ocasiones, la mejor manera de darla a conocer es a través de charlas, debates, actividades de sensibilización, etc... Con la llegada de este Libro Blanco se pretende dar un giro a la Educación Ambiental, dándole mayor importancia a programas educativos para prevenir -programas educativos destinados a los factores sociales incidiendo en un cambio de valores y comportamientos, extendiendo a todos los sectores la Educación Ambiental y fomentando la participación ciudadana-. Hoy en día, pese a mucho camino recorrido y muchos años de dedicación a ello, aún es un tema desconocido para la población. Pese a su gran expansión a lo largo del tiempo, aún sigue siendo algo inalcanzable para todos. El poco interés por cuidar del mundo futuro o la falta de conocimientos para ello sigue siendo un impedimento para seguir avanzando hacia la sostenibilidad y la educación ambiental. Por ello, muchos son los Educadores que día a día luchan desde la Educación Formal y la Educación Informal para que esto cambie con iniciativas para sensibilizar sobre la manera de ayudar y no obstaculizar el proceso de respeto hacia el medio en el que vivimos, desde reciclar, usar vehículos eléctricos hasta usar fuentes renovables (Perales Palacios y Aguilera Morales, 2018; Barba, 2019; Perales-Palacios, 2020). 
Desde la Educación Formal, será necesario abordar los Objetivos de Desarrollo Sostenible -ODS- para que de esta manera, los alumnos puedan desarrollar una educación encaminada hacia la organización y el funcionamiento correcto de la gestión ambiental, así como fomentar su participación de los mismos a la hora de buscar soluciones hacia la problemática del medio en el que vivimos, haciendo referencia a la contaminación, el cambio climático, etc., y de esta manera acercarlos hacia la reflexión y a la práctica hacia la evaluación de la calidad. Desde la década de los 90 , las granjas escuelas han estado muy presentes para abordar la temática de la Educación Ambiental, las cuales han aumentado de manera notoria a lo largo de los años, incluyendo del mismo modo las aulas de la naturaleza, centros de interpretación, huertos ecológicos... De esta manera, han ido reforzando a la Educación Formal, desde una Educación no Formal (Benayas, Gutiérrez, Hidalgo y Marcén, 2017; Perales-Palacios, 2020). Será muy importante también abogar por una educación intergeneracional e intercomunitaria, "comprende los conocimientos derivados de los valores propios y de nuestra época y civilización (Martínez y Rodríguez, 2017, p.114). De esta manera, la Educación Intergeneracional, permitirá abordar cuatro pilares básicos para que se desarrolle de una manera adecuada a lo largo de la vida: en primer lugar, enseñar a vivir de manera conjunta, de esta manera, se aportarán beneficios mutuos entre diferentes generaciones. En segundo lugar, enseñar a conocer a los demás y estar en contacto con ellos. En tercer lugar, enseñar a hacer a través de la interacción y reflexión. Por último, enseñar a ser, para poder realizarse como persona de manera individual y colectiva (Bedmar, 2003, citado en Martínez y Rodríguez, 2017).

Muchos son los profesionales de la educación, que día a día luchan por una Educación Ambiental en las aulas. Los profesores no tienen el papel de rector, sino el de acompañante durante el proceso de aprendizaje y adquisición de acciones adecuadas para el medioambiente, encaminadas hacia la sostenibilidad. Tal y como dice Benayas et al (2017):

\begin{abstract}
"Construir una cultura de la sostenibilidad en la escuela supone un continuado proceso de reflexión-acción-reflexión, necesita ofrecer espacios reales de participación democrática y toma de decisiones, debe plantearse si es necesaria una evolución del papel docente, debería desarrollar competencias comunicativas en escenarios reales y hacer propuestas de cambio y ejecutarlas. La posterior evaluación de los procesos y resultados obtenidos en los cambios daría sentido a la participación" (pp. 20).
\end{abstract}

Según la Convención sobre los Derechos del Niño de la ONU (Unicef, 2006), destinada a promover y proteger los derechos de la infancia, dedica el artículo 29 a la E.A en la infancia y a la ciudadanía responsable:

“(a) Preparar al niño para asumir una vida responsable en una sociedad libre, con espíritu de comprensión, paz, tolerancia, igualdad de sexos y amistad entre todos los pueblos, grupos étnicos, nacionales religiosos y personas de origen indígena. (b) Inculcar al niño el respeto del medio ambiente natural" (pp. 19-20).

Muchos son los problemas o las enfermedades derivadas de riesgos ambientales, como puede ser las provocadas por la contaminación o por las aguas residuales. Benayas et al. (2017) en su informe de Educación para la Sostenibilidad, cuando habla del futuro, habla de diferentes acciones que se deben llevar a cabo para un futuro sostenible y que incluya la Educación Ambiental:

- Reflexión sobre los cambios en la enseñanza para que los alumnos se impliquen más en la Educación Ambiente.

- Trabajo en valores de cara al futuro. 
- Existencia de contenidos y procedimientos para la sostenibilidad en cada una de las etapas educativas en los ODS.

- Reuniones y congresos de ámbito estatal entre todos los educadores.

- Transmisión de más habilidades y competencias al alumnado y menos contenido.

- Modelos de enseñanza adecuados para los Educadores. Los cuales deberán abordar aspectos teóricos y metodológicos.

- La comunidad educativa estará implicada en la toma de decisiones, asunción de compromisos y empoderamiento del alumnado.

- Fortalecimiento del trabajo en red de centros educativos y universidades.

- Los jóvenes deberán ser agentes del cambio.

- Educomunicación. Será muy importante debido a las grandes tecnologías con las que se cuenta hoy en día, como son las redes sociales y los medios de comunicación. Hay que tenerlas muy en cuenta y trabajar con ellas en todo momento para hacer llegar la información a los jóvenes.

\section{Objetivos}

Objetivo general:

- Mejorar la Educación Ambiental en el ámbito escolar e intercomunitario en el municipio de Polopos - La Mamola con el fin de contribuir al desarrollo sostenible de sus habitantes.

Objetivos específicos:

- Concienciar a la población de la importancia de la flora autóctona del municipio con la realización de actividades relacionada con las chumberas.

- Conservar y potenciar los beneficios del mar y la playa del municipio.

\section{Metodología}

\section{Herramientas de análisis y estudio}

Como herramientas de análisis y estudio de la zona se ha visto conveniente elegir DAFO y CAME. Siendo ambas adecuadas para ver las debilidades, amenazas, fortalezas y oportunidades del proyecto que se llevará a cabo, así como buscarles soluciones a ellas y potenciarlas.

En las siguientes tablas se muestra ambos análisis, DAFO y CAME. 
Tabla 1. DAFO

\section{DEBILIDADES}

- Desinformación acerca del desarrollo sostenible y la Educación Ambiental.

- Poco interés por realizar acciones adecuadas hacia el medioambiente.

- Falta de concienciación, sensibilización y formación acerca de los beneficios de los recursos que nos ofrece el medio en el que vivimos.

-Falta de interés por conservar las chumberas en el municipio.

\section{AMENAZAS}

-Falta de inversión de los organismos públicos para la conservación de las chumberas.

-Escasa concienciación de los habitantes del municipio, así como de los turistas acerca del mar o la montaña.

- Explotación del terreno.

\section{FORTALEZAS}

-Diversidad de recursos con gran riqueza y de ecosistemas, como es el mar y la montaña.

-Territorio adecuado para el crecimiento de las chumberas.

-Territorio con un gran potencial para la realización de actividades al aire libre.

\section{OPORTUNIDADES}

- Imagen externa positiva debido a que es un lugar vinculado a los recursos naturales y medioambientales.

-Crecimiento del municipio como un lugar con gran valor patrimonial gracias al uso adecuado de los recursos ambientales del mismo.

-Unión intergeneracional e intercomunitaria hacia la Educación Ambiental.

Tabla 2. CAME

\section{CORREGIR DEBILIDADES}

-Ofrecer información a la población sobre la Educación Ambiental y la sostenibilidad.

- Llevar a cabo diferentes acciones para incrementar el interés de la población por la E.A.

-Concienciar, sensibilizar y formar a la población sobre la temática.

- Ofrecer todo tipo de información acerca de las chumberas, así como sus beneficios para que la población tome conciencia de la importancia de estas en el entorno.

\section{AFRONTAR AMENAZAS}

- Llevar a cabo mercadillos de recaudación de dinero.

- Concienciar a la población a través de actividades sobre la importancia de cuidar el mar y la montaña, ya que es beneficioso para todos los seres vivos.

-Visibilizar los espacios naturales de la zona para evitar sobreexplotaciones del terreno.

\section{EXPLORAR OPORTUNIDADES}

-Realización de actividades con diferentes colectivos para fortalecer las relaciones intergeneracionales y aprender unos de otros.

- Llevar a cabo acciones para que el municipio sea un lugar visitado por su gran patrimonio cultural realizando excursiones de colegios, IMSERSO, institutos, etc.

\section{MANTENER FORTALEZAS}

-Potenciar los recursos que ofrece la naturaleza con actividades al aire libre.

-Plantar chumberas en la zona.

- Realización de talleres medioambientales al aire libre 


\section{Propuesta de intervención}

En la propuesta de intervención de este proyecto se llevarán a cabo actividades intergeneracionales e intercomunitarias en las que esté presente la recuperación de la flora de la zona como es las chumberas y actividades en las que se esté en contacto con el mar.

Se pretende una unión entre diferentes generaciones y comunidades, llevando a cabo actividades en las que estén en contacto ambas, a la vez que se potencia y enriquece la zona. Estas actividades se realizarán tanto para población de la zona como para excursiones que vengan de fuera, ya sean escolares, familiares, de edad adulta o ancianos. Se ofrecerá la posibilidad de realizar la actividad que deseen, según sus preferencias.

El lugar de realización de estas actividades será en el municipio de Polopos (La Mamola, Granada). Se promocionará a través de un tríptico (ver ANEXO 1) y la difusión por redes sociales -Instagram-@proyectoMamolasostenible- se darán a conocer estas actividades a toda la población.

\section{Actividades}

A continuación, se enuncian y describe las actividades propuestas en fichas:

\begin{tabular}{|l|l|}
\hline Nombre & Vivero de Chumberas \\
\hline Descripción & $\begin{array}{l}\text { En esta actividad se realizará un vivero de chumberas, para recuperar la } \\
\text { flora tan característica del municipio. La actividad se dividirá en diferentes } \\
\text { partes: } \\
\text { Primera parte: Los grupos serán de } 7 \text { participantes aproximadamente. } \\
\text { Se explicará a los participantes que es un vivero y la importancia de este, } \\
\text { así como se hablará de la planta de las chumberas y los beneficios de } \\
\text { estas. Tras esto, se comenzará la explicación para poder plantarla y sus } \\
\text { cuidados. Del mismo modo, se repartirá a cada participante dos semillas } \\
\text { de chumberas (una de ellas será para sembrarla en el vivero, otra para } \\
\text { sembrarla en un macetero para llevársela a sus casas). } \\
\text { Cada participante diseñará un cartel pequeño con el nombre de la planta } \\
\text { y el suyo y pegarán un palo para mantener el cartel de pie e incrustarlo en } \\
\text { la arena, para más tarde, ponerlo al lado de la semilla plantada. Del mismo } \\
\text { modo, el macetero lo decorarán también. } \\
\text { Toda explicación se hará con los participantes en un círculo, sentados } \\
\text { alrededor de la Educadora. } \\
\text { Segunda parte: Los participantes se levantarán e irán todos a la zona de } \\
\text { plantación (la zona la decidirán los profesionales). Si previamente, han } \\
\text { asistido otros grupos, se les mostrará el crecimiento de la planta. } \\
\text { Se comenzará la preparación de fertilizante natural con café y agua. } \\
\text { Preparación: Media taza de café de agua, por cada cucharada de café } \\
\text { soluble. Se echarán dos - tres cucharadas a la planta. Esto permitirá que } \\
\text { las plantas se nutran de nitrógeno y crezcan más fuertes. }\end{array}$ \\
\hline
\end{tabular}




\begin{tabular}{|c|c|}
\hline & $\begin{array}{l}\text { Tras esto, se comenzará a plantar las semillas en la tierra y a preparar el } \\
\text { terreno para ello con fertilizantes naturales y agua. Del mismo modo se } \\
\text { plantará en los maceteros individuales también. } \\
\text { Tercera parte: Volverán al punto de partida, donde se reunían todos los } \\
\text { participantes en círculo para hacer una reflexión sobre la sesión. }\end{array}$ \\
\hline Temporalización & 4 horas \\
\hline Precio & $5 €$ \\
\hline Objetivos & $\begin{array}{l}\text { Recuperar la flora autóctona. } \\
\text { Conocer el proceso de plantación de las chumberas y sus cuidados. } \\
\text { Ser conscientes de la importancia de las plantas. }\end{array}$ \\
\hline Participantes & Infancia, juventud y grupos familiares. \\
\hline Recursos & $\begin{array}{l}\text { Recursos humanos: Dos Educadoras por cada grupo de } 7 \text { personas. } \\
\text { Recursos materiales: } \\
\text { - Semillas de chumbera } \\
\text { - Agua } \\
\text { - Tierra } \\
\text { - Maceteros } \\
\text { - Pala } \\
\text { - Témperas } \\
\text { - Pinceles } \\
\text { - Cartulina } \\
\text { - Rotuladores } \\
\text { - Palos de pinchitos } \\
\text { Recursos espaciales: en esta actividad se realizará todo al aire libre por } \\
\text { el pueblo de La Mamola. }\end{array}$ \\
\hline Evaluación & $\begin{array}{l}\text { Se les harán diferentes preguntas para conducirlos hacia un pequeño } \\
\text { debate entre todos: } \\
\text { - ¿Qué os ha parecido la experiencia? } \\
\text { - ¿Os habéis sentido cómodos? } \\
\text { - ¿Habéis recibido ayuda o habéis ayudado? } \\
\text { - ¿Obéis aprendido cosas nuevas? } \\
\text { - ¿Os gustaría repetir? }\end{array}$ \\
\hline Variaciones & $\begin{array}{l}\text { Las preguntas del debate podrán modificarse, dependiendo del colectivo } \\
\text { al que vayan dirigidas. }\end{array}$ \\
\hline
\end{tabular}




\begin{tabular}{|c|c|}
\hline Nombre & Ruta de las Chumberas \\
\hline Descripción & $\begin{array}{l}\text { Se realizará una ruta por la Rambla y la Torre de Cautor (La Mamola). } \\
\text { Se harán grupos de } 10 \text { personas aproximadamente, guiadas por una } \\
\text { Educadora. Durante el trayecto se realizarán varias paradas (5): } \\
\text { Primera parada: explicación del origen de las chumberas y la } \\
\text { importancia de estas en nuestro entorno. } \\
\text { Segunda parada: comentar la pérdida de esta planta en la zona. } \\
\text { Tercera parada: durante el camino, se encontrarán chumberas que } \\
\text { previamente se han plantado otros usuarios, las observaremos y } \\
\text { regaremos. } \\
\text { Cuarta parada: ACTIVIDAD. } \\
\text { En esta parada, se realizará una actividad para conocer mejor las } \\
\text { semillas de las chumberas. } \\
\text { Se realizarán dos grupos, uno de ellos irá con la Educadora } 1 \text {, el otro } \\
\text { con la Educadora } 2 \text {. } \\
\text { Se podrán tres cuencos en el suelo, en alguna piedra o en una mesa si } \\
\text { disponen de ella, los cuales contendrán } 3 \text { tipos de semillas diferentes } \\
\text { (chumberas, calabacines y zanahorias). Uno por uno tocará los tres } \\
\text { cuencos y deberán adivinar, con los ojos tapados, cuál de las tres } \\
\text { semillas es la de la chumbera. } \\
\text { Tras esto, se les preguntará a los participantes si conocen los cuidados } \\
\text { de las chumberas, si es así, que hablen de ello. Posteriormente, se les } \\
\text { hará una serie de preguntas: } \\
\text { - ¿Creéis que las plantas necesitan agua para poder sobrevivir? } \\
\text { ¿Será más beneficioso el agua de la lluvia o la que echa el ser } \\
\text { humano? } \\
\text { - ¿Cuánto tiempo creéis que tarda una chumbera en crecer hasta la } \\
\text { edad adulta? } \\
\text { les explicarán todas las preguntas y se responderán. } \\
\text { las chumberas necesitan estar mucho tiempo al sol? } \\
\text { le la chumbera creéis que se come? }\end{array}$ \\
\hline Temporalización & 4 horas. \\
\hline Precio & $4 €$ \\
\hline Objetivos & $\begin{array}{l}\text { - Valorar los recursos ambientales que ofrece el pueblo. } \\
\text { - Conocer la historia de las chumberas y ser conscientes de la } \\
\text { importancia de estas. }\end{array}$ \\
\hline Participantes & Infancia, juventud, grupos familiares, edad adulta o anciana. \\
\hline Recursos & $\begin{array}{l}\text { Recursos humanos: Dos Educadoras por cada } 10 \text { participantes. } \\
\text { Recursos materiales: } \\
\text { - Semillas de calabacín, zanahoria y chumberas. }\end{array}$ \\
\hline
\end{tabular}




\begin{tabular}{|l|l|}
\hline & $\begin{array}{l}\text { Cuencos. } \\
\text { Agua, algo para tomar por el camino (si así lo desean los } \\
\text { participantes). } \\
\text { Recursos espaciales: la ruta se realizará por la rambla de Cautor y la } \\
\text { torre. }\end{array}$ \\
\hline Evaluación & $\begin{array}{l}\text { Una vez finalizado el recorrido, se realizará una evaluación tocando } \\
\text { aspectos como: ¿Os habéis sentido bien?, ¿habéis aprendido algo } \\
\text { nuevo?, ¿os gustaría repetir?, ¿recomendarias esta ruta a amigos o } \\
\text { familiares? }\end{array}$ \\
\hline Variaciones & $\begin{array}{l}\text { El camino podrá adaptarse, dependiendo del colectivo. Se podrá ir por } \\
\text { lugares más complicados o sencillos. La actividad final podrá tener } \\
\text { variaciones en sus preguntas dependiendo, del mismo modo del } \\
\text { colectivo al que irá destinada. }\end{array}$ \\
\hline
\end{tabular}

\begin{tabular}{|c|c|}
\hline Nombre & Clase de Yoga para principiantes \\
\hline Descripción & $\begin{array}{l}\text { Los grupos serán de } 15 \text { personas como máximo, podrán ser mixtos (de } \\
\text { todas las edades). Anteriormente, se informará a los participantes, tras } \\
\text { inscribirse en la actividad, que deberán asistir con ropa cómoda y de color } \\
\text { blanco, una esterilla, un cojín y una manta. } \\
\text { Se realizará una clase de yoga, con movimientos básicos para } \\
\text { principiantes y adaptados a todas las edades. } \\
\text { Se comenzará con una explicación e introducción a la disciplina del yoga. } \\
\text { Tras esto, comenzará la clase, de la mano de un especialista en la } \\
\text { disciplina. } \\
\text { La clase de yoga se realizará, si el tiempo lo permite, al aire libre, en el } \\
\text { mar, para estar en contacto con el mismo, escuchando el sonido de las } \\
\text { olas y sintiendo la arena en cada parte de nuestro cuerpo. } \\
\text { Al finalizar la clase, se caminará por la orilla del mar, para fortalecer, con } \\
\text { el agua fría la circulación. }\end{array}$ \\
\hline Temporalización & 3 horas. \\
\hline Precio & $4 €$ \\
\hline Objetivos & $\begin{array}{l}\text { Tener un contacto con la naturaleza y conocer los beneficios del mar en } \\
\text { nuestro cuerpo. } \\
\text { Conectar con el entorno que nos rodea. }\end{array}$ \\
\hline Participantes & Juventud, edad adulta y ancianos. \\
\hline Recursos & $\begin{array}{l}\text { Recursos humanos: } \\
\text { - Una Educadora. } \\
\text { - Una profesora de Yoga. }\end{array}$ \\
\hline
\end{tabular}




\begin{tabular}{|c|c|}
\hline & $\begin{array}{l}\text { Recursos materiales: } \\
\text { - Esterilla. } \\
\text { - Manta. } \\
\text { - Cojín. } \\
\text { Recursos espaciales: la playa. }\end{array}$ \\
\hline Evaluación & $\begin{array}{l}\text { La evaluación de esta actividad se realizará sentados en las esterillas. Se } \\
\text { comentará la clase de yoga, los sentimientos, las sensaciones que han } \\
\text { tenido y los beneficios de realizar la clase cerca del mar, en continuo } \\
\text { contacto con él. }\end{array}$ \\
\hline Variaciones & $\begin{array}{l}\text { Si el tiempo no permitiese realizar la clase al aire libre, se realizaría en el } \\
\text { pabellón del colegio, con música relajante de fondo, como podría ser el } \\
\text { sonido del mar y los pájaros piar. }\end{array}$ \\
\hline
\end{tabular}

\begin{tabular}{|c|c|}
\hline Nombre & Taller de Decora un Souvenir \\
\hline Descripción & $\begin{array}{l}\text { Antes de empezar el taller de decoración de Souvenir, las Educadoras } \\
\text { explicarán lo característico de la zona, por ejemplo, la Torre de Cautor, la } \\
\text { playa, la montaña, que ha sido un pueblo de pescadores, etc. De esta } \\
\text { manera, pondremos en contexto a los participantes y tendrán un amplio } \\
\text { abanico de posibilidades para decorar los souvenirs. } \\
\text { En este taller se da la opción de pintar/ decorar piedras, camisetas o } \\
\text { maceteros. } \\
\text { Se harán tres grupos, uno por cada artículo a decorar. Cada participante } \\
\text { elegirá según sus preferencias ir hacia un grupo u otro. } \\
\text { La actividad se realizará en el mar, si el tiempo lo permite. Serán } \\
\text { necesarias unas mesas y sillas, así como materiales de decoración } \\
\text { (pintura para ropa, tizas de colores, rotuladores permanentes, etc.). } \\
\text { Pintar piedras: Puesto que estaremos en la playa, la primera tarea de } \\
\text { este taller será buscar la mejor piedra para pintar. Entre todos, paseando } \\
\text { por la playa, buscarán la mejor. } \\
\text { Tras esto, se llevará a la mesa y comenzarán a decorarlas. El tema con el } \\
\text { que tiene que estar relacionado será La Mamola. } \\
\text { Para pintar las piedras se podrá usar pintura acrílica, rotuladores o tizas } \\
\text { de colores. Al finalizar la pintura se dará una capa de cola blanca para fijar } \\
\text { la pintura. } \\
\text { Pintar camisetas: Los participantes deberán traer una camiseta. Todas } \\
\text { las camisetas deberán ser blancas o de algún color claro, para que, de } \\
\text { esta manera, se aprecie mejor el dibujo. } \\
\text { Los participantes se colocarán alrededor de la mesa de trabajo y } \\
\text { comenzarán a crear su diseño. Nuevamente la temática será La Mamola. } \\
\text { Podrán usar las pinturas para ropa para ello. } \\
\text { Pintar maceteros: Los maceteros serán cubos de pintura vacíos, latas o } \\
\text { cualquier otro objeto en forma de macetero, de diferente tamaño. Estos } \\
\text { serán ofrecidos por las Educadoras. }\end{array}$ \\
\hline
\end{tabular}




\begin{tabular}{|c|c|}
\hline & $\begin{array}{l}\text { Los participantes se reunirán alrededor de la mesa de trabajo y } \\
\text { comenzarán la actividad. } \\
\text { Para decorar los maceteros se podrá usar abalorios, pegatinas, pintura } \\
\text { acrílica. } \\
\text { Una vez más, el tema elegido para la decoración de estos será La } \\
\text { Mamola. } \\
\text { Al finalizar de decorar los abalorios, cada participante deberá hacer un } \\
\text { simulacro como si estuviese o quisiera vender su souvenir a los demás } \\
\text { participantes. Quien mejor lo haga, recibirá un recuerdo. Solo podrá haber } \\
\text { un ganador por cada grupo. Los ganadores los elegirán sus compañeros } \\
\text { a través de los aplausos. A un mayor número de ruido en el aplauso, más } \\
\text { puntos obtendrá. } \\
\text { El recuerdo/premio será un llavero de La Mamola. }\end{array}$ \\
\hline Temporalización & 3 horas. \\
\hline Precio & $5 €$ \\
\hline Objetivos & $\begin{array}{l}\text { Estar en contacto con el mar mientras se realizan actividades relajantes } \\
\text { como puede ser pintar. } \\
\text { Conocer el municipio de Polopos - La Mamola. }\end{array}$ \\
\hline Participantes & Infancia, juventud, adultos, grupos familiares y ancianos. \\
\hline Recursos & $\begin{array}{l}\text { Recursos humanos: Una Educadora por cada grupo (3). } \\
\text { Recursos materiales: } \\
\text { - Pegatinas } \\
\text { - Abalorios } \\
\text { - Pintura acrílica } \\
\text { - Pinceles } \\
\text { - Cola blanca } \\
\text { - Cabos } \\
\text { - Piedras } \\
\text { - } 3 \text { llaveros de recuerdo } \\
\text { - Rotuladores } \\
\text { - Pizas } \\
\text { - Papel de cocina } \\
\text { - Vasua } \\
\text { Recursos de plástico para echar la pintura } \\
\text { Mamola. }\end{array}$ \\
\hline Evaluación & $\begin{array}{l}\text { Para evaluar la actividad se realizará una charla entre todos los } \\
\text { participantes para comentar que les ha parecido los talleres y así poder } \\
\text { captar posibles mejoras y conocer los sentimientos de ellos. }\end{array}$ \\
\hline Variaciones & $\begin{array}{l}\text { Si el tiempo no lo permitiese, la actividad se realizaría en el gimnasio del } \\
\text { Colegio de La Mamola. }\end{array}$ \\
\hline
\end{tabular}




\section{Temporalización}

La duración de las actividades del proyecto será de 4 meses, de febrero hasta mayo, en horario de mañana, de 9:00 a 14:00 horas. Puesto que se dispondrá de cuatro actividades para elegir, se realizarán dos días a la semana, siendo los martes y jueves los días para ello. Dedicando cada semana del mes a una de esas actividades, como se indica en el siguiente calendario o cronograma.

\section{Cronograma}

\begin{tabular}{|l|l|l|l|l|l|l|l|l|l|l|l|l|l|l|l|l|}
\hline & \multicolumn{2}{|l|}{ FEBRERO } & \multicolumn{2}{l|}{ MARZO } & \multicolumn{3}{l|}{ ABRIL } & \multicolumn{3}{l|}{ MAYO } \\
\hline SEMANAS & $\mathbf{1}$ & $\mathbf{2}$ & $\mathbf{3}$ & $\mathbf{4}$ & $\mathbf{1}$ & $\mathbf{2}$ & $\mathbf{3}$ & $\mathbf{4}$ & $\mathbf{1}$ & $\mathbf{2}$ & $\mathbf{3}$ & $\mathbf{4}$ & $\mathbf{1}$ & $\mathbf{2}$ & $\mathbf{3}$ & $\mathbf{4}$ \\
\hline Vivero de Chumberas & & & & & & & & & & & & & & & & \\
\hline Ruta de las Chumberas & & & & & & & & & & & & & & & \\
\hline Clase de Yoga para principiantes & & & & & & & & & & & & & & & & \\
\hline Taller Decora un Souvenir & & & & & & & & & & & & & & & & \\
\hline
\end{tabular}

\section{Evaluación}

La estrategia de Recogida de información elegida será el Cuestionario (ver ANEXO 2) y la Rúbrica (ver ANEXO 3). La finalidad del Cuestionario será comprobar si los objetivos de nuestro proyecto se han llevado a cabo de manera correcta a lo largo de la realización de las diversas actividades realizadas.

La participación en este cuestionario será voluntaria y sus respuestas serán anónimas y confidenciales, por lo tanto, se rogará a las personas que participen en él, total sinceridad sus respuestas.

El cuestionario se repartirá a los participantes una vez acabada la sesión. Para colectivos como el de infancia o juventud, el cuestionario se realizará de manera oral, entre todos los participantes.

Con la Rúbrica, evaluaremos criterios y objetivos, a los participantes y a su vez, realizaremos una autoevaluación, reflexión y revisión de las actividades realizadas. Los profesionales serán los encargados de realizar esta evaluación durante el desarrollo de la actividad.

\section{Conclusiones}

Como conclusión, podemos señalar que tras el análisis de necesidades con las herramientas de recogida de información DAFO y CAME, se puede comprobar el escaso potencial que se le saca al mar y a la montaña en el municipio de Polopos (La Mamola, Granada), a los beneficios de ambos en el desarrollo adecuado de la vida de las personas. Por otro lado, la educación ambiental, y con ella el adecuado desarrollo sostenible, en el ámbito escolar e intercomunitario es escaso. De esta manera, será necesario concienciar a la población autóctona y externa de la importancia de este, para de esta manera llevar a cabo acciones en nuestra vida diaria que potencien los recursos naturales del mar y la flora de la montaña, en este caso de la planta de las chumberas. 
Del mismo modo, será de especial interés que la población conozca el porqué de la pérdida de esta planta y problemas que está ocasionando su pérdida.

Vemos conveniente intervenir y llevar a cabo este proyecto en este, ya que es un paradero casi desconocido para la mayoría de las personas, el cual consta con una gran riqueza patrimonial y natural. Encontrándose tanto el mar como la montaña unidos a escasos metros entre sí. Donde la flora, la fauna y los seres humanos conviven en un conjunto casi sin ser conscientes de ello. Este proyecto no está centrado en un solo sector de la población, está destinado a todas las edades, ya que consideramos de gran importancia trabajar estos temas con toda la población, sin importar la edad.

Tanto las actividades realizadas en la montaña como las actividades realizadas en el mar son beneficiosas, ya que se pretende un contacto directo con el entorno natural, para que de esta manera la población vea los beneficios de estas y puede, en su vida diaria, llevar a cabo acciones sostenibles y de cuidado al medio ambiente, para que estos beneficios sigan funcionando por mucho tiempo.

Las cuatro actividades del proyecto son complejas y es recomendable realizar las cuatro en diferentes momentos en la vida cotidiana de los participantes para que la visita al municipio deje huella tanto en los participantes como en el municipio.

\section{Referencias}

Aguilera Morales, D y Perales Palacios, FJ (2016). Metodología participativa en ciencias naturales: implicación en el rendimiento académico y la actitud hacia la ciencia del alumnado de Educación Primaria. ReiDoCrea, 5, 119-129. Doi:10.30827/Digibug.41450

Barba, M (2019). Limites e indefiniciones de la educación ambientas, un debate permanente. RES, 28(1), 9-31.

Benayas del Álamo, J, Marcén, C, Hidalgo, DA y Gutiérrez, JM (2017). Educación para la Sostenibilidad en España. Reflexiones y propuestas. Madrid: Fundación Alternativas: Red Española para el Desarrollo Sostenible.

Comisión Temática de Educación Ambiental (Ed.) (1999). Libro Blanco de la Educación Ambiental en España. Madrid: Ministerio de Medio Ambiente.

Flores, RC (2012). Investigación en Educación Ambiental. Revista mexicana de investigación educativa, 17(55), 1019-1033.

Martínez Heredia, N y Rodríguez García, AM (2018). Educación intergeneracional un nuevo reto para la formación del profesorado. REXE, 17(33), 113-124.
Ministerio de Medio Ambiente (Ed.) (1999). Libro Blanco de La Educación Ambiental en España en pocas palabras. Madrid: Ministerio de Medio Ambiente.

Novo, M (1996). La Educación Ambiental formal y no formal: dos sistemas complementarios. Revista Iberoamericana de Educación, 11, 75-102.

Perales-Palacios, FJ (2020). Experiencias previas en educación ambiental de una muestra de estudiantes del grado de educación social. REIDOCREA, 9, 93-106. Doi:10.30827/Digibug.66360

Perales Palacios, FJ. y Aguilera Morales, D. (2018). ¿Podemos cambiar nuestros comportamientos ambientales? Un estudio descriptivo con alumnos universitarios. ReiDoCrea, 7, 151166.

Rengifo, BA, Quitiaquez, L y Mora, FJ (2012). La educación ambiental una estrategia pedagógica que contribuye a la solución de la problemática ambiental en Colombia. XII Coloquio internacional de Geocrítica, 16, 1-16.

UNICEF (2006). Convención sobre los Derechos del Niño. Madrid: UNICEF. 


\section{Anexos}

\section{ANEXO 1 - TRÍPTICO}

¿Os gustaria disfrutar de la naturaleza del municipio y conocer los rincones tan maravillosos que se esconden en el?
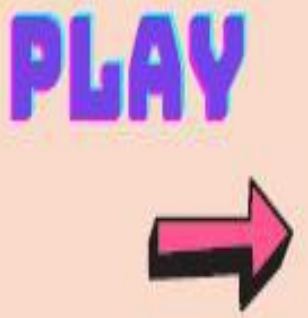

Contacto:

Oficina:

C/ Escuelas, 1. La Mamola.

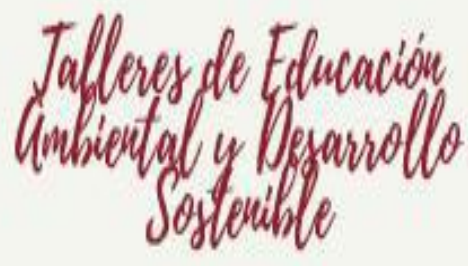

Teléfono: 644585421

Email:

educacionambientallamamola@gmail.com

Preguntar por: Tania Rubia

\section{LA MAMOLA}

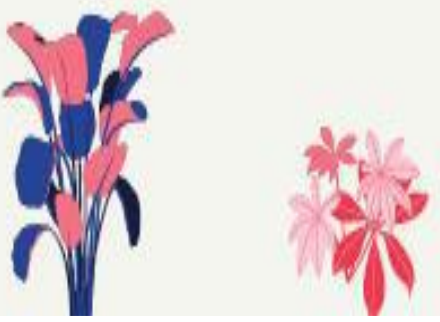




\section{ANEXO 2 - CUESTIONARIO}

En el presente cuestionario aparecerán una serie de preguntas sobre las actividades que habéis realizado. Marca con una $x$ la respuesta correcta. Rogamos sinceridad en todo momento. Muchas gracias de antemano.

Género: $\square$ Mujer $\square$ Hombre $\square$ Otro

1. ¿Conocías el concepto de Medio Ambiente anteriormente?

$$
\square \text { Sí } \square \text { No }
$$

2. ¿Conocías el concepto de Sostenibilidad anteriormente?

$$
\square \text { Sí } \square \text { No }
$$

3. ¿Has realizado alguna actividad anteriormente cómo la que habéis realizado hoy?

$$
\square \text { Sí } \square \text { No }
$$

4. ¿Crees que son actividades destinada a todos los colectivos?

$$
\square \text { Sí } \square \text { No }
$$

5. ¿Te gustaría realizar alguna de las demás actividades ofertadas en el Proyecto?

$$
\square \text { Sí } \square \text { No }
$$

¿Cuál de ellas?

$\square$ Vivero de Chumberas

$\square$ Ruta de las Chumberas

$\square$ Clase de Yoga para principiantes

口Taller Decora un Souvenir

6. ¿Has recibido ayuda de tus compañeros?

$$
\square \text { Sí } \square \text { No }
$$

Responde a las siguientes preguntas únicamente si has realizado alguna de las siguientes actividades: "Vivero de Chumberas" o "Ruta de las Chumberas"

7. ¿Sabías la importancia de las chumberas para el medio en el que vivimos?

$$
\square \text { Sí } \square \text { No }
$$

8. ¿Has conocido información que antes no tenías sobre esta planta?

$$
\square \text { Sí } \square \text { No }
$$

9. Te has interesado en algún momento por la pérdida de esta planta en tan poco tiempo?

$$
\square \text { Sí } \square \text { No } \square \text { Tal vez }
$$

Responde a las siguientes preguntas únicamente si has realizado alguna de las siguientes actividades: "Clase de Yoga para Principiantes" o "Decora un Souvenir".

10. ¿Crees que te ha aportado beneficios realizar la actividad cerca del mar?

$$
\square \text { Sí } \square \text { No }
$$

11. Elige la mejor opción.

Si tuvieses que realizar de nuevo la actividad, ¿dónde preferirías hacerla?

$\square$ Playa $\square$ Montaña $\square$ Lugar cerrado (ejemplo un gimnasio)

12. ¿Consideras relajante el sonido del mar?

$$
\square \text { Sí } \square \text { No }
$$


ANEXO 3 - RÚBRICA

\begin{tabular}{|c|c|c|c|c|}
\hline & EXCELENTE & BIEN & REGULAR & MAL \\
\hline \multicolumn{5}{|l|}{ Prestan atención a la actividad } \\
\hline \multicolumn{5}{|l|}{ Muestran interés por la actividad } \\
\hline \multicolumn{5}{|c|}{ Intervienen y responden a las preguntas } \\
\hline \multicolumn{5}{|c|}{$\begin{array}{l}\text { Toman consciencia de la importancia de las chumberas en el } \\
\text { municipio }\end{array}$} \\
\hline \multicolumn{5}{|c|}{ Se sienten relajados y a gusto al realizar la actividad } \\
\hline Respetan a los compañeros & & & & \\
\hline Cooperan entre los participantes & & & & \\
\hline
\end{tabular}

